\title{
Erratum to: Common Hematological Disorders in Children
}

\author{
Deepak Bansal • Sidharth Totadri
}

Published online: 26 April 2014

(C) Dr. K C Chaudhuri Foundation 2014

Erratum to: Indian J Pediatr (January 2014) 81(1):42-50

DOI 10.1007/s12098-013-1159-8

The paper was published bearing incorrect data. On page 43 of Issue 1, Vol 81 (January 2014) under the heading "How to Treat IDA?", the last line should read as "Patient should be dewormed" instead of "Patient should be deformed".

The online version of the original article can be found at http://dx.doi.org/ 10.1007/s12098-013-1159-8.

D. Bansal $(\bowtie) \cdot$ S. Totadri Pediatric Hematology-Oncology Unit, Department of Pediatrics, Advanced Pediatric Centre, Post Graduate Institute of Medical Education and Research, Chandigarh 160012, India

e-mail: deepakbansaldr@gmail.com 